mental health clinicians need to be more proactive with their patients by first educating themselves and then their patients. Most importantly, the book takes away the white handkerchief of defeat that clinicians tend to hold up when faced with patients with personality disorder, and replaces it with effective tools to understand personality disorders and manage patients confidently and appropriately. Incorporating this in 66 pages makes this informative book by Dr Newton-Howes a must-have for every clinician.

Zainib Khan CT1 Psychiatry Trainee, Stratheden Hospital, NHS Fife, 19 Aytoun Road, Glasgow G41 5H, UK. Email: zainibkhan@nhs.net

doi: 10.1192/bjp.bp.115.166199

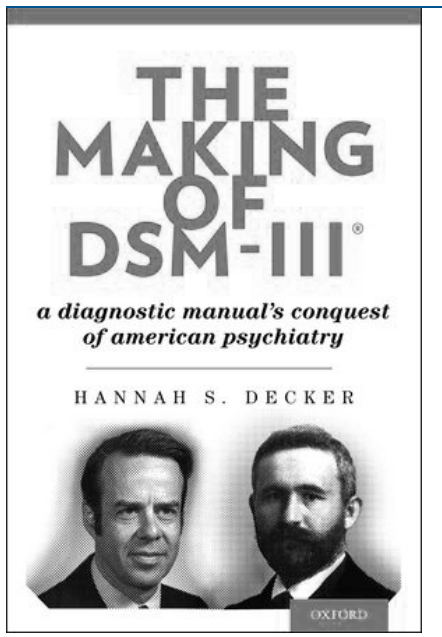

\section{The Making of DSM-III: A Diagnostic Manual's Conquest of American Psychiatry}

By Hannah S. Decker

Oxford University Press USA. 2013

£35.99 (pb). 466 pp.

ISBN 9780195382235

This book describes the history of the most important edition of the American Psychiatric Association's diagnostic manual: DSM-III, which came out in 1980, was a truly revolutionary document. Decker puts this story in a wider historical context. American psychiatry faced criticism from many quarters, including colleagues from other specialties, and felt particularly vulnerable about the reliability of its diagnoses. Only a few academics, most of whom worked at Washington University in St Louis, had focused on these issues.

The main character in this book is Robert Spitzer, a Columbia University professor whose portrait is next to that of Emil Kraepelin on the cover of the book. Spitzer adopted the views of the St Louis group, namely that in the absence of biomarkers, psychiatric diagnosis has to be made on the basis of systematic observation and phenomenology. Spitzer, a former psychoanalyst, had moved into psychometrics, but was also a brilliant politician. Often under attack, particularly from psychoanalysts, Spitzer almost always emerged victorious. The new system replaced prototypical descriptions (still to be found in the International Classification of Diseases) with algorithmic criteria that had the potential to make diagnosis more reliable. The DSM system was a convenient way of classifying disorders that were poorly understood (and remain so). It was never intended to be a treatment manual, although it has often been used that way, with clinicians conducting routine symptom checks instead of exploring life histories. As biological theories came to dominate the American system, that problem has not got any better.

Decker has gone to primary sources and interviewed key players to find out how decisions were actually made. What makes this book outstanding is its analysis of medical politics. We would like to believe that diagnostic manuals are based on empirical data. In psychiatry, this is not yet possible. Decker's book shows how outcomes often depend on which physicians are most influential and powerful.

This story is also highly relevant in view of the recent publication of DSM-5, which ignited a story of controversy that was also based on medical politics. While DSM-5 is not radically different from DSM-III, every change stirred up a storm of disagreement. It remains to be seen whether the upcoming ICD-11 system will produce similar levels of criticism. It also remains to be seen whether the research domain criteria proposed by the National Institute of Mental Health offer a viable alternative. It is likely that the diagnostic system cannot become more valid until research illuminates the true causes of mental disorders. In summary, this book tells a story that was relevant 35 years ago and remains relevant today.

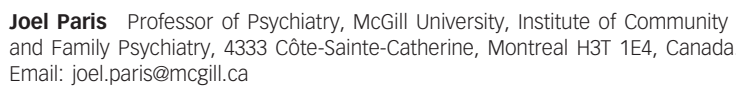

Joel Paris Professor of Psychiatry, McGill University, Institute of Community and Family Psychiatry, 4333 Côte-Sainte-Catherine, Montreal H3T 1E4, Canada. Email: joel.paris@mcgill.ca

doi: 10.1192/bjp.bp.113.138297

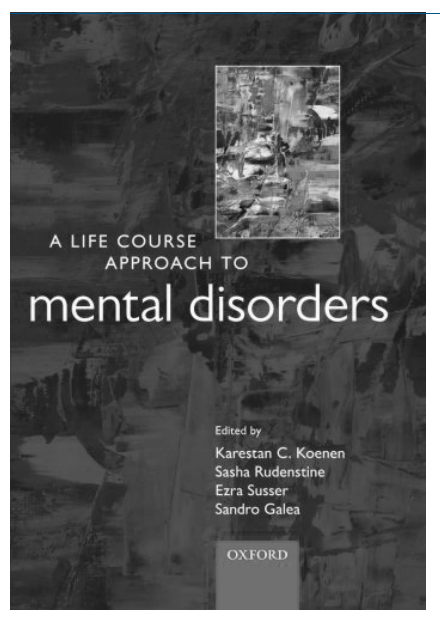

\section{A Life Course Approach} to Mental Disorders

Edited by Karestan C. Koenen, Sasha Rudenstine, Ezra Susser \& Sandro Galea. Oxford University Press, 2013 $£ 44.99$ (pb). $336 \mathrm{pp}$. ISBN 9780199657018

The life course approach to physical health has been modelled in previous publications by Oxford University Press; this is the first book to apply the concept to the theory of the development of psychiatric illness. From the effect of population-wide lead levels on the prevalence of schizophrenia, to the genetic risk factors for starting smoking, this book provides a wide-ranging critical overview of current theories and evidence for the aetiology of common mental disorders. The approach - part epidemiology, part sociology, genetics, public health, psychology, child development, and more appears to be uniquely suitable when analysing the complex reasons why people develop mental illness.

For example, in chapter 6 the aetiology of schizophrenia is discussed in depth: genetic risk factors are analysed; maternal lifestyle and illness in pregnancy addressed; childhood cognitive development discussed, as well as biological and social factors; and later-life risk factors analysed. Contributing data are critically analysed, and include recently published prospective cohort data and large population-based studies, as well as twin and retrospective studies. A similar approach is taken to each mental illness in turn, in each case thoroughly and clearly presented.

The most involving chapter is the final conclusion, which outlines the few published studies of interventions aimed at the 